\title{
Behaviour of Corroded Stud Shear Connectors under Fatigue Loading
}

\author{
Ju Chen, Ao-Yu Jiang, and Wei-Liang Jin \\ Department of Civil Engineering, Zhejiang University, Hangzhou, China
}

\begin{abstract}
Experimental investigation was conducted on corroded composite push-out specimens to study the behavior of shear studs subjected to fatigue loading. A total of eight standard EC4 push-out specimens were tested. The expected corrosion rate of test specimens ranged from 0 to $50 \%$. The main purpose of these tests was to determine the fatigue life and the reduction effect caused by the corrosion on the fatigue life. The effect of corrosion on the fatigue crack, load-slip curves, and failure modes was also studied. In addition, the test results were compared with current Eurocode design predictions, which is only for specimen without corrosion. It is shown that the current Eurocode design predictions are quite conservative for the test specimens in this study. Design equations were also proposed for fatigue life of corroded composite push-out specimens.
\end{abstract}

\section{INTRODUCTION}

Normally, shear connectors are used at the steel and concrete interface to provide interaction between the concrete slab and steel girder. Headed stud shear connectors are the most common type of shear connectors and are used in steel-concrete composite bridges for its economic and fast application. Especially in bridges due to traffic actions, these studs are subjected to high-cycle fatigue loading. Most of the data on connectors have been obtained from various types of push-out test. Since the 1960s, various researchers have conducted a great number of cyclic push-out tests to determine the fatigue life of shear connectors (Akao, Kurita, \& Hiragi, 1982; Feldmann, Gesella, \& Leffer, 2006; Feldmann, Hechler, Hegger, \& Rauscher, 2008; Hanswille, Porsch, \& Ustundag, 2007; Johnson, 2000; Leea, Shimb, \& Changc, 2005; Nakajima et al., 2003; Oehlers, 1989; Slutter \& Driscoll, 1965; Veljkovic \& Johansson, 2006)

Although safety factor in initial design may delay the occurrence of fatigue problems, the priori negligence of corrosion pits in structural integrity analysis may lead to significant overestimation of the damage tolerance ability of existing steel structures (Petroyiannis, Kermanidis, \& Akid, 2005). There is lack of protection between the concrete slab and steel girder interface and also makes corrosion difficult to be detected. The corrosion will damage the studs and the steel girders.

Corrosion fatigue, which refers to the joint interaction of corrosive environment and repeated dynamic stressing, is more detrimental than that of either one acting separately (Stephens, Ratemi, Stephens, \& Fuchs, 2000). Bridges, which serve as a major link component in the infrastructure system, are extremely vulnerable to the combined action of corrosion and fatigue. The action could possibly bring major threats on structural safety and lead to catastrophic failure, such as the tragedy of the collapse of the Silver Bridge in 1967 (LeRose, 2001). Recent research has been carried out on the corrosion fatigue behavior of reinforcing bar or steel beams in the bridge (Apostolopoulos, 2007; Kashani, Lowes, Crewe, \& Alexander, 2014; Xu \& Wang, 2015; Zhang \& Yuan, 2014). It is shown that corrosion-induced fatigue strength reduction has a large effect on fatigue life. Fatigue life could reduce more than $60 \%$ for the low corrosion condition and more than $70 \%$ for the medium and high corrosion condition. However, there is lack of corrosion fatigue behavior of shear stud connector for composite bridges. This paper deals with the results of the experimental studies on the behaviour of corroded headed shear studs subjected to unidirectional cyclic loading. Based on the test results, load-slip curves and ultimate strengths of specimens having different corrosion rates were evaluated. In addition, the suitability of current design equations for corrode stud shear connectors was also evaluated.

\section{EXPERIMENTAL INVESTIGATION}

\subsection{Test specimens}

Test specimens were fabricated according to the standard push test specimen specified in Annex B of Eurocode (2004). Slabs of $150 \mathrm{~mm}$ thickness were used, and bond at the interface between the flanges of steel beam and the concrete slab was prevented by greasing the flange. Each of both concrete slabs was 
cast in the horizontal position, as is done for composite beams in practice, and the push test specimens were air cured. The details of the specimens are shown in Figure 1. The test specimens were labeled that the excepted corrosion rate could be identified from the label. For example, the labels "SPS-10" and "FPS-00-1" define the specimens as follow:

- The first three letters "SPS" and "FPS" refer to static push test specimen and fatigue push test specimen, respectively.

- The following two digits (00 and 20 ) indicate the expected corrosion rates of stud in percentage.

- The last digit "1," "2," or "3" indicates the test specimens having the same corrosion rate but different load amplitude.
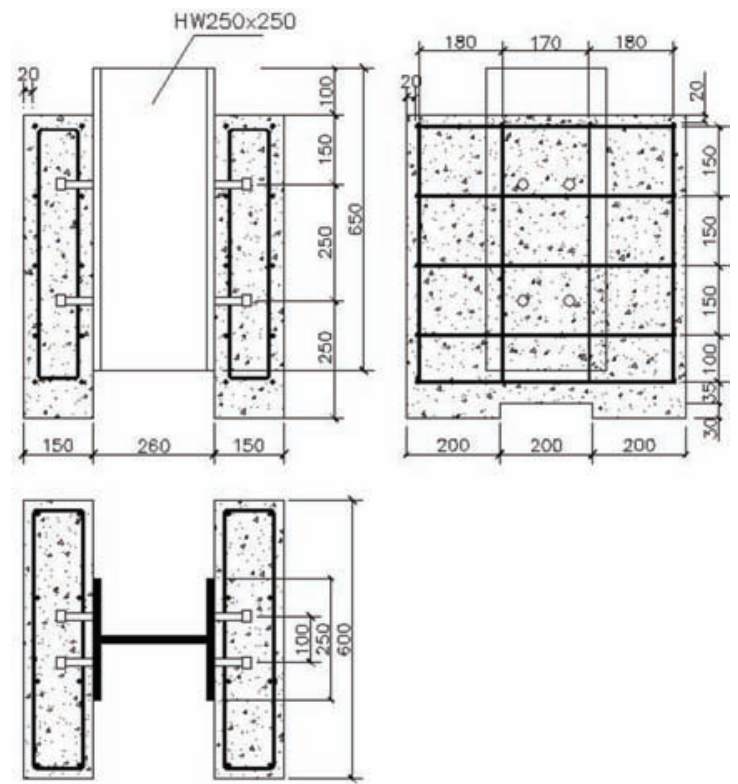

Figure 1. Details of push-out test specimens.

\subsection{Material properties and measurements}

Three concrete cubic specimens were prepared at the time of push test specimen casting, to determine the concrete strength of the push test specimens. Table 1 summarizes the material properties of concrete at 28 days. Studs with the nominal diameter of 10.0 are used in this study. Tensile tests for the stud material were conducted. The yield stress from the tensile tests was determined by $0.2 \%$ strain, because the steel for studs generally does not show clear yielding point. The yield strength and tensile strength of stud material are 275 and $392.3 \mathrm{MPa}$, respectively, whereas the elastic modulus is $1.94 \times 10^{5} \mathrm{MPa}$. Quality control of welding process is a very important factor since the effect of welding quality may cover the effect of corrosion. Therefore, welding trials were carried out to obtain proper and reliable welding quality.
Table 1. Material properties of concrete.

\begin{tabular}{lcc}
\hline Specimen & $\boldsymbol{E}_{c}(\mathrm{MPa})$ & $\boldsymbol{f}_{c u}(\mathrm{MPa})$ \\
\hline 1 & $3.31 \times 10^{4}$ & 43.9 \\
2 & $3.36 \times 10^{4}$ & 44.3 \\
3 & $3.38 \times 10^{4}$ & 45.2 \\
Average & $3.35 \times 10^{4}$ & 44.5 \\
\hline
\end{tabular}

\subsection{Accelerating corrosion process}

All specimens, except the uncorroded one (control specimen), were immersed in a $5 \% \mathrm{NaCl}$ solution for 3 days after cured for 28 days, then the direction of current about $0.2 \mu \mathrm{A} / \mathrm{cm}^{2}$ was arranged for accelerating stud corrosion, studs worked as the anodes, whereas a piece of stainless steel positioned in the solution served as cathode, as shown in Figure 2. The I-section steel beam was isolated by epoxy resins, so that corrosion only occurs at the stud and steel-concrete interface, as shown in Figure 2. The corrosion time of each specimen was determined based on the expected corrosion rate. The Faraday's theory is used to calculate the corrosion time. The calculated results are shown in Table 2. It should be noted that the actual corrosion rates of test specimens may differ from those expected corrosion rates.

Table 2. Excepted stud corrosion rate and actual corrosion time of test specimens.

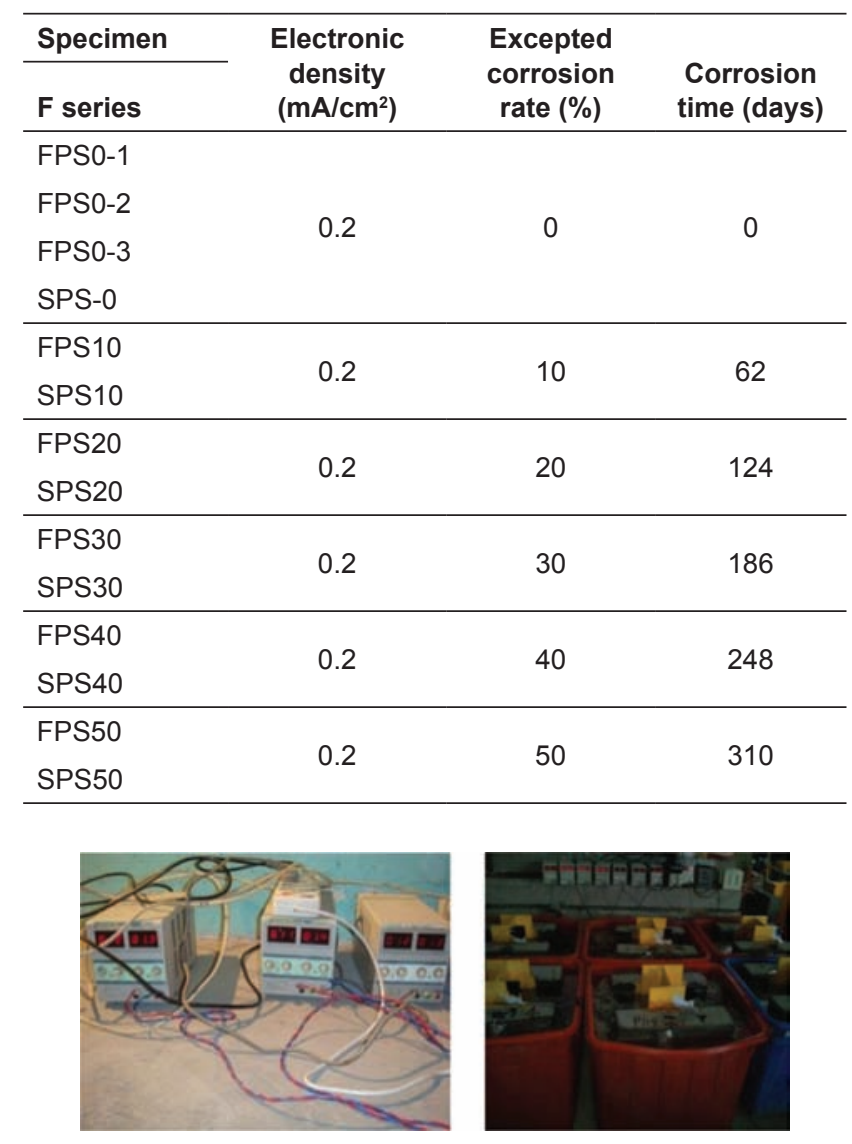

Figure 2. Electronic accelerating corrosion of push test specimens. 


\subsection{Loading test setup and procedure}

The experimental program consists of a total of two series test specimens. In the first series, static tests were performed to determine the ultimate static load $P_{u}$ of the corroded push-out specimen, as shown in Table 3. The static testing procedure complied with the method specified in Eurocode 4 Annex B (2004). The ultimate static load represents the relative values of loading parameter required for cyclic tests for the second series tests. Using the relative loading parameters, load-controlled cyclic test was performed to determine the fatigue life $N_{u}$ of the push-out specimen. The maximum load $\left(P_{F-\max }\right)$ and minimum load $\left(P_{F-\min }\right)$ for the cyclic test were $0.65 P_{U}$ and $0.45 P_{u}$, respectively. The chosen maximum and minimum load for each specimen are summarized in Table 3.

Table 3. Static ultimate strength and corresponding fatigue load of test specimens.

\begin{tabular}{lcccc}
\hline & $\begin{array}{c}\text { Static ultimate } \\
\text { strength }\end{array}$ & & \multicolumn{2}{c}{ Fatigue test load } \\
\cline { 2 - 2 } \cline { 5 - 5 } Specimen & $\boldsymbol{P}_{U}(\mathbf{k N})$ & & $\boldsymbol{P}_{F-\max }(\mathbf{k N})$ & $\boldsymbol{P}_{F-\min }(\mathbf{k N})$ \\
\hline SPS0 & 344 & & 222 & 160 \\
SPS10 & 326 & & 211 & 146 \\
SPS20 & 299 & & 193 & 134 \\
SPS30 & 270 & & 176 & 122 \\
SPS40 & 241 & & 158 & 109 \\
SPS50 & 215 & & 140 & 97 \\
\hline
\end{tabular}

Corroded push test specimens were loaded in an Instron 8805 fatigue testing machine with loading capacity of $1000 \mathrm{kN}$, as shown in Figure 3. The slabs are bedded onto the lower platen of the testing machine, and load is applied to the upper end of the steel section. Slip between the steel member and the two slabs is measured using LVDTs. The data were obtained by a CRONOS compact 400-08 acquisition instrument. The monotonic tests were conducted at a displacement rate of $0.3 \mathrm{~mm} / \mathrm{min}$. The time taken to reach the ultimate load was about $40 \mathrm{~min}$. Cyclic tests were conducted with a load frequency of $7 \mathrm{~Hz}$.

During the tests, the time load from the actuator load cell, ram displacement from the built-in transducer in the actuator, longitudinal displacement between the concrete slab and steel beam, and uplift of the slabs were measured. The ram displacement included movement due to the compliance of the test rig, and therefore, it was not used in any subsequent data analysis. The longitudinal displacements were measured by two LVDTs on each steel flange to which the studs were welded, as shown in Figure 3.
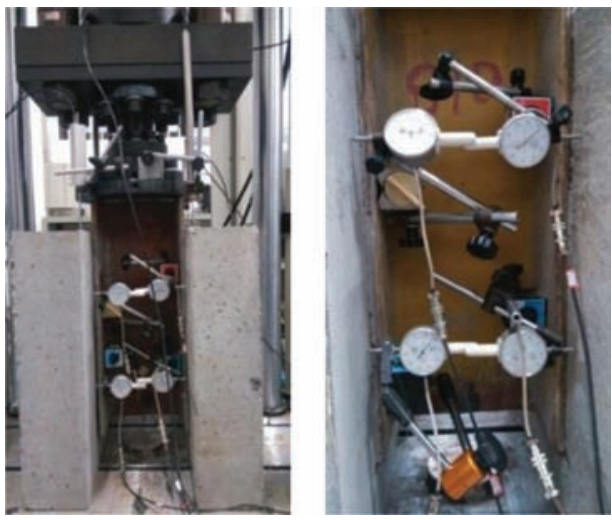

Figure 3. Test setup.

\section{TEST RESULTS}

\subsection{Measurement of stud corrosion rate}

The corroded studs were retrieved from the failed specimens and the corrosion product was cleaned using a corrosion-inhibited $\mathrm{HCl}$ solution (Bertoa, Simionib, \& Saettab, 2008), as shown in Figure 4. It is shown that the corrosion is uneven distributed. With increasing corrosion time, pits corrosion gradually transformed to wide-shallow pit (Xu \& Wang, 2015). The area loss of the steel stud $(\Delta \mathrm{A})$ was estimated afterwards by subtracting the post-corrosion area from the measured pre-corrosion area. The post-corrosion area of stud was calculated using the measured diameter of the shank of the stud. The measured diameter of the shank was used to calculate the corrosion rate of each stud $(\psi)$ as: $\psi=(\mathrm{A}-\Delta \mathrm{A}) / \mathrm{A} \%$. The average corrosion rate of eight studs is taken as the corrosion rate of each push test specimen, as shown in Table 4. It is shown that the measured corrosion rates of push test specimens are different from those expected corrosion rates. Although all those studs failed at the bottom of the shank, the corrosion rate along the whole length of the shank provides a reasonable description of the corrosion state.

Table 4. Measured corrosion rates of test specimens.

\begin{tabular}{lcc}
\hline Specimen & $\begin{array}{c}\text { Excepted corrosion } \\
\text { rate (\%) }\end{array}$ & $\begin{array}{c}\text { Measured corrosion } \\
\text { rate (\%) }\end{array}$ \\
\hline FPS10 & 10.0 & 5.42 \\
SPS10 & 10.0 & 5.31 \\
FPS20 & 20.0 & 16.87 \\
SPS20 & 20.0 & 19.02 \\
FPS30 & 30.0 & 25.02 \\
SPS30 & 30.0 & 28.40 \\
FPS40 & 40.0 & 34.59 \\
SPS40 & 40.0 & 36.02 \\
FPS50 & 50.0 & 47.04 \\
SPS50 & 50.0 & 51.62 \\
\hline
\end{tabular}




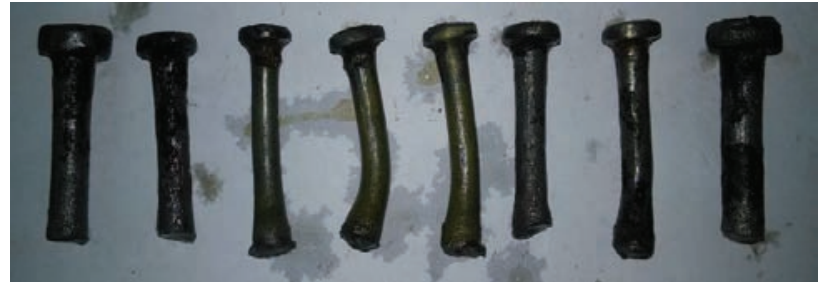

(a) Studs of specimen FPS-10

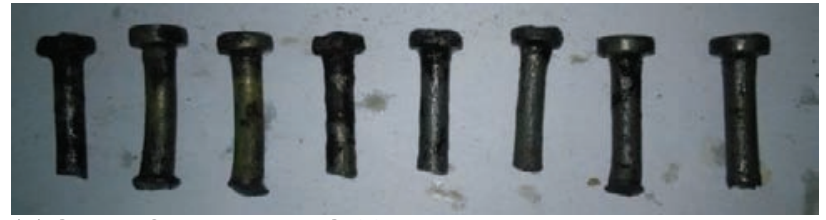

(b) Studs of specimen FPS-30

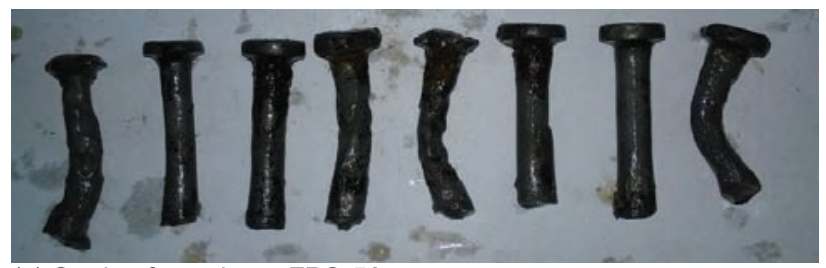

(c) Studs of specimen FPS-50

Figure 4. Corroded studs of test specimens.

\subsection{Static strength}

In this study, the failure mode of all push test specimens is stud failure. Figure 5 shows typical stud failure of the test specimens. The ultimate strengths of test specimen series are shown in Table 3. It is shown that the ultimate strengths of test specimens decrease when the corrosion rate increases. The maximum ultimate strength reduction rate of test specimen SPS series is $62.5 \%$. It means that the corrosion has significant effect on the ultimate strengths of test specimens.

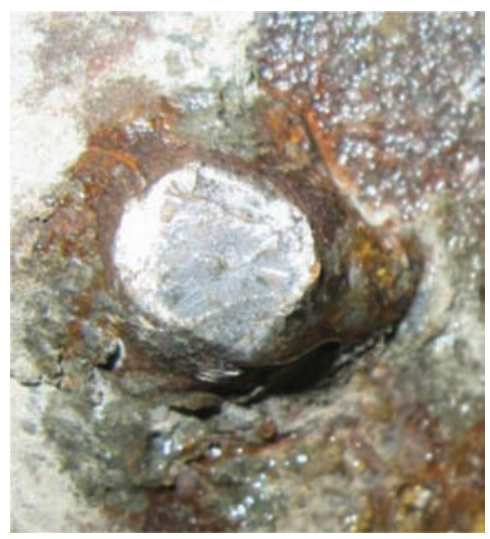

Figure 5. Stud fracture surface of specimen SPS-20.

\subsection{Fatigue test results and discussion}

\subsubsection{Failure mode}

To investigate the reasons for the reduction of the fatigue life, the concrete slabs were separated from the steel beam, and the fractured surfaces at the foot of each headed stud were examined. The examined fracture surfaces consist of the typical dull fatigue fracture and bright forced fracture zones, where in the fatigue tests the former one is formed by cracks propagating to a critical length and the second one due to forced shear fracture (Van der Walde \& Hillberry, 2007). Typical fracture of fatigue specimen FPS40 is shown in Figure 6. It is different from the fracture surface of the stud in static test, as shown in Figure 5.

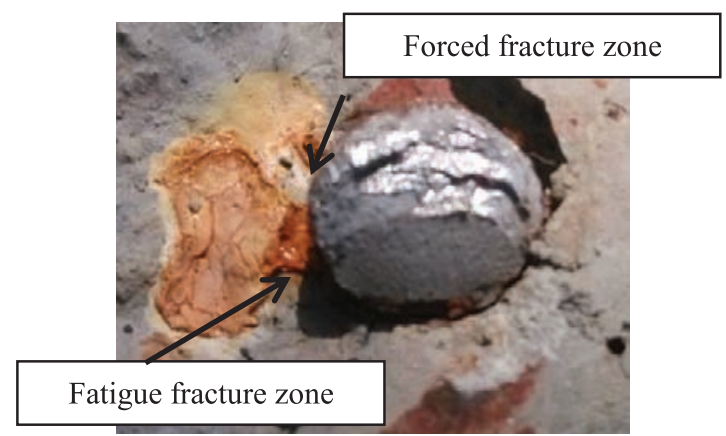

Figure 6. Stud fracture surface of specimen FPS-40.

\subsubsection{Fatigue life}

It can be seen that the fatigue resistances of corroded specimens gradually decreased and their fatigue life ranged from 30 to $80 \%$ compared with the uncorroded specimens, as shown in Tables 5 and 6 . This is much better than the observations of other investigators (Xu \& Qiu, 2013) who reported fatigue life reduction of about six to eight times for pitted steel specimens under constant amplitude tension-tension loading. The reason may be that the applied cyclic load decreased when the corrosion rate of specimens increased in this study. Another reason may be that the fracture position always at the bottom of the shank, where may not be the place of deepest corrosion pit as specimen in tension.

Table 5. Comparison of fatigue life prediction with test results of uncorroded test specimens.

\begin{tabular}{|c|c|c|c|c|c|c|}
\hline Specimens & $\begin{array}{c}\Delta \tau_{n} \\
\left(\mathrm{~N} / \mathrm{mm}^{2}\right)\end{array}$ & $\begin{array}{c}N_{\mathrm{t}} \\
\left(10^{4}\right)\end{array}$ & $\begin{array}{l}N_{\mathrm{R}, \mathrm{EC} 4} \\
\left(10^{4}\right)\end{array}$ & $\begin{array}{c}N_{\mathrm{R}, \text { prop1 }} \\
\left(10^{4}\right)\end{array}$ & $\frac{N_{\mathrm{R}, \mathrm{EC} 4}}{\boldsymbol{N}_{\mathrm{t}}}$ & $\frac{N_{\text {R,prop1 }}}{N_{t}}$ \\
\hline FPS0-1 & 149.2 & 23.9 & 5.4 & 23.8 & 0.226 & 0.918 \\
\hline FPSO-2 & 119.4 & 92.0 & 32.1 & 93.0 & 0.349 & 1.027 \\
\hline \multirow[t]{3}{*}{ FPSO-3 } & 102.8 & 183.4 & 106.3 & 182.1 & 0.579 & 1.055 \\
\hline & & & & Mean & 0.385 & 1.000 \\
\hline & & & & COV & 0.381 & 0.059 \\
\hline
\end{tabular}

3.3.3 Maximum slip at every load cycle

In case of cyclic loading the load-deformation behavior is characterized by an increasing slip and a decreasing elastic stiffness. In Figure 7, the maximum slip corresponding to the peak load at every cycle is plotted against the number of cycles for fatigue test 
Table 6. Comparison of fatigue life prediction calculated using nominal stress with test results of corroded test specimens.

\begin{tabular}{lcccccc}
\hline & $\begin{array}{c}\Delta \tau_{n}(\mathbf{N} / \\
\left.\mathbf{m m}^{2}\right)\end{array}$ & $\begin{array}{c}\boldsymbol{N}_{\mathrm{t}} \\
\left(\mathbf{1 0 ^ { 4 } )}\right.\end{array}$ & $\begin{array}{c}\boldsymbol{N}_{\mathrm{R}, \mathrm{EC} 4} \\
\left(\mathbf{1 0 ^ { 4 } )}\right.\end{array}$ & $\begin{array}{c}\boldsymbol{N}_{\mathrm{R}, \mathrm{prop} 2} \\
\left(\mathbf{1 0 ^ { 4 } )}\right.\end{array}$ & $\begin{array}{c}\boldsymbol{N}_{\mathrm{R}, \mathrm{EC} 4} \\
\text { Specimens }\end{array}$ & $\frac{\boldsymbol{N}_{\mathrm{R}, \text { prop2 }}}{\boldsymbol{N}_{\mathrm{t}}}$ \\
\hline FPS10 & 107.8 & 80 & 72.8 & 94.8 & 0.910 & 1.185 \\
FPS20 & 97.8 & 72 & 158.0 & 74.7 & 2.195 & 1.038 \\
FPS30 & 89.5 & 70.5 & 320.9 & 60.1 & 4.552 & 0.852 \\
FPS40 & 81.3 & 53.5 & 698.2 & 47.3 & 13.050 & 0.884 \\
FPS50 & 71.3 & 32 & 1985.2 & 34.3 & 62.036 & 1.072 \\
\hline & & & & Mean & - & 1.006 \\
& & & & COV & - & 0.123 \\
\hline
\end{tabular}

specimens. The beginning and the end of the lifetime are associated with a steep increase in the maximum slip with the number of cycles, whereas in the remaining part of the lifetime a nearly linear increase of the maximum slip occurs with the number of cycles. The steep increase in the maximum slip at the end of lifetime occurs earlier for specimens having larger corrosion rate. The maximum slip value at each cycle increased with the increasing corrosion rate. It may be explained that the corrosion reduce the fatigue performance of the stud connectors.

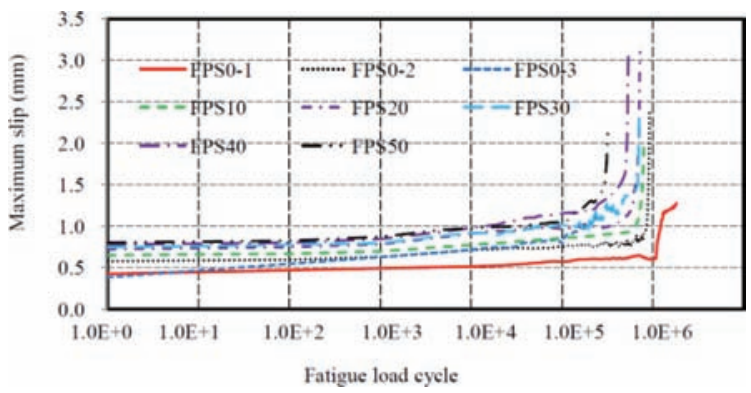

Figure 7. Maximum slip at each fatigue load cycle.

\section{DESIGN METHOD OF FATIGUE LIFE}

Current Eurocode (2004) provides design method for the fatigue life of uncorroded stud, as shown in Eq. (1). The design shear resistance of a headed stud in accordance with Eurocode 4 should be determined from:

$$
\left(\Delta \tau_{R}\right)^{m} N_{R}=\left(\Delta \tau_{c}\right)^{m} N_{c}
$$

where $N_{R}$ is the fatigue life corresponding to the load amplitude $\Delta \tau_{R} ; \Delta \tau_{\mathrm{C}}$ is the load amplitude at the reference point, $\Delta \tau_{c}=95.0 \mathrm{~N} / \mathrm{mm}^{2} ; N_{c}$ is the fatigue life at the reference point, $N_{c}=2,000,000 ; m$ is the parameter, $\mathrm{m}=8$.

The design strengths predicted using Eurocode (2004) are compared with test results of uncorroded specimens in Table 6. It is shown that the design predictions are very conservative as it is stated in the Eurocode 4. A new equation is proposed based on
Eq. (1) by using curve fitting method, as shown Eq. (2). It is shown that the prediction from the proposed equation agree with the test results well.

$$
N_{\mathrm{R}, \text { prop } 1}=\left(\frac{102.2}{\Delta \tau_{R}}\right)^{5.540} \times 200
$$

For the corroded specimens, Eq. (1) was also used to predict the fatigue life. However, two kinds of stress amplitude were used, one is the nominal stress and the other is real stress. The nominal stress is calculated by using the cross-section area of uncorroded stud connectors. The real stress is calculated by using the reduced cross-section area of corroded stud connectors. The fatigue life of corroded test specimens predicted using the nominal stress was shown in Table 7 and Figure 8 . It is shown that the fatigue life increased with the increasing corrosion rate. This is caused by the reduced nominal stress calculated using the reduced load but unchanged cross-section area of stud connectors. The curve fitting equation of the nominal stress prediction was shown in Eq. (3), which is only for comparison in Figure 8.

$$
N_{\mathrm{R}, \text { prop2 }}=\left(\frac{146.0}{\Delta \tau_{R}}\right)^{-2.460} \times 200
$$

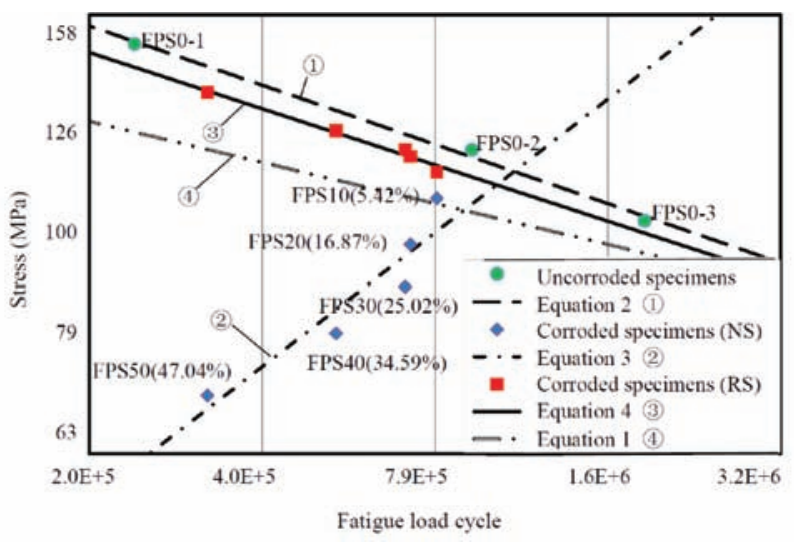

Figure 8. Comparison of design prediction with test results.

Table 7. Comparison of fatigue life prediction calculated using real stress with test results of corroded test specimens.

\begin{tabular}{lclllll}
\hline & $\begin{array}{c}\Delta \tau_{n} \\
\text { Specimens }\end{array}$ & $\begin{array}{c}\left.\boldsymbol{N}_{\mathbf{t}} / \mathbf{m m}^{2}\right) \\
\left(\mathbf{1 0 ^ { 4 } )}\right.\end{array}$ & $\begin{array}{c}\boldsymbol{N}_{\text {R,EC4 }} \\
\left(\mathbf{1 0}^{4}\right)\end{array}$ & $\begin{array}{c}\boldsymbol{N}_{\text {R,prop2 }} \\
\left(10^{4}\right)\end{array}$ & $\frac{\boldsymbol{N}_{\text {R,EC4 }}}{\boldsymbol{N}_{\mathbf{t}}}$ & $\frac{\boldsymbol{N}_{\text {R,prop3 }}}{\boldsymbol{N}_{\mathbf{t}}}$ \\
\hline FPS10 & 114.0 & 80 & 46.6 & 86.4 & 0.583 & 1.080 \\
FPS20 & 117.7 & 72 & 36.0 & 71.6 & 0.501 & 0.994 \\
FPS30 & 119.4 & 70.5 & 32.1 & 65.7 & 0.455 & 0.932 \\
FPS40 & 124.2 & 53.5 & 23.4 & 52.2 & 0.437 & 0.976 \\
FPS50 & 134.6 & 32 & 12.3 & 32.6 & 0.384 & 1.020 \\
\hline & & & & Mean & 0.472 & 1.000 \\
& & & & COV & 0.142 & 0.049 \\
\hline
\end{tabular}


The fatigue life of corroded test specimens predicted using the real stress was shown in Table 7 and Figure 8. It is shown that the fatigue life decreased with the increasing corrosion rate, which means that the corrosion reduce the fatigue performance of the stud connectors. The curve fitting equation of the real stress prediction was shown in Eq. (4). It is shown that the fitting curve agree with the test results well, as shown in Figure 8. It is also shown that the Eurocode 4 predictions using the real stress are very conservative. However, the load in the practical engineering structures nominal remains constant during the whole life of the structures. Thus, the real stress will increased with the increasing corrosion rate of stud connectors, which may result in the further reduction of fatigue life.

$$
N_{\text {R,prop3 }}=\left(\frac{98.7}{\Delta \tau_{R}}\right)^{5.838} \times 200
$$

\section{CONCLUSION}

Fatigue test of steel and concrete composite push test specimens with corrosion deterioration was conducted in this study. Static test was also conducted for ultimate strength reference. The test specimens were first electronic accelerating corroded then loaded to failure. All specimens failed in stud connectors' facture failure. Based on the test results, the effect of corrosion on the maximum slip at each load cycle and fatigue life was studied. It is shown that the maximum slip value at each cycle increased with the increasing corrosion rate. It is also shown that the fatigue life increased with the increasing corrosion rate at the similar load amplitude. Test results obtained from the loading tests were compared with fatigue life predicted by current Eurocode 4. It is shown that the fatigue life was very conservative for uncorroded specimens. New design equation with reasonably accuracy was proposed, which enables the designer to consider the effect of corrosion on the fatigue life.

\section{ACKNOWLEDGMENT}

The research work described in this paper was supported by research projects from Science and Technology Department of Zhejiang Province (2015C33005).

\section{REFERENCES}

Akao, S., Kurita, A., \& Hiragi, H. (1982). Fatigue strength of stud shear connectors with concrete deposited from different placing directions. In: IABSE Fatigue, Lausanne, Switzerland.
Apostolopoulos, C. A. (2007). Mechanical behavior of corroded reinforcing steel bars S500s tempcore under low cycle fatigue. Constructional and Building Materials, 21, 1447-1456.

Bertoa, L., Simionib, B., \& Saettab, B. (2008). Numerical modelling of bond behaviour in RC structures affected by reinforcement corrosion. Engineering Structures, 30(7), 1375-1385.

EN 1994-1-1. (2004). Eurocode 4: Design of composite steel and concrete structures Part 1-1: General rules and rules for buildings.

Feldmann, M., Gesella, H., \& Leffer, A. (2006). The cyclic force-slip behaviour of headed studs under non static service loads experimental studies and analytical descriptions. Composite Construction in Steel and Concrete, 5, 564-572.

Feldmann, M., Hechler, O., Hegger, J., \& Rauscher, S. (2008). Fatigue behavior of shear connectors in high performance concrete. Composite Construction in Steel and Concrete, 6, 39-51.

Hanswille, G. E., Porsch, M. A., \& Ustundag, C. (2007). Resistance of headed studs subjected to fatigue loading. Journal of Constructional Steel Research, 63(3), 475-484.

Johnson, R. P. (2000). Resistance of stud shear connectors to fatigue. Journal of Constructional Steel Research, 56(1), 101-116.

Kashani, M. M., Lowes, L. N., Crewe, A. J., \& Alexander, N. A. (2014). Finite element investigation of the influence of corrosion pattern on inelastic buckling and cyclic response of corroded reinforcing bars. Engineering Structures, 75(1), 113-125.

Leea, P., Shimb, C., \& Changc, S. (2005). Static and fatigue behavior of large stud shear connectors for steel-concrete composite bridges. Journal of Constructional Steel Research, 61(11), 1270-1285.

LeRose, C. (2001). The collapse of the Silver Bridge. West Virginia hist soc quart, XV(4).

Nakajima, A., Saiki, I., Kokai, M., Doi, K., Takabayashi, Y., \& Ooe, H. (2003). Cyclic shear force-slip behavior of studs under alternating and pulsating load condition. Engineering Structures, 25(4), 537-545.

Oehlers, D. J. (1989). A new approach to the design of stud shear connectors in composite bridge beams (Research Report R82). University of Adelaide.

Petroyiannis, P. V., Kermanidis, A. T., \& Akid, R. (2005). Analysis of the effect of exfoliation corrosion on the fatigue behavior of the 2024-T351 aluminum alloy using the fatigue damage map. International Journal of Fatigue, 27, 817-827.

Slutter, R., \& Driscoll, G. C. (1965). Flexural strength of steel-concrete composite beams. Journal of Structural Engineering, ASCE, 71-99. 
Stephens, R. I., Ratemi, A., Stephens, R. R., \& Fuchs, H. O. (2000). Metal fatigue in engineering (2nd ed.). New York, NY: John Wiley \& Sons.

Van der Walde, K., \& Hillberry, B. M. (2007). Initiation and shape development of corrosion nucleated fatigue cracking. International Journal of Fatigue, 29(7), 1269-1281.

Veljkovic, M., \& Johansson, B. (2006). Residual static resistance of welded stud shear connectors. Composite Construction in Steel and Concrete, 5, 524-533.
Xu, S., \& Qiu, B. (2013). Experimental study on fatigue behavior of corroded steel. Materials Science and Engineering: A, 584(1), 163-169.

Xu, S., \& Wang, Y. (2015). Estimating the effects of corrosion pits on the fatigue life of steel plate based on the 3D profile. International Journal of Fatigue, 72(1), 27-41.

Zhang, W., \& Yuan, H. (2014). Corrosion fatigue effects on life estimation of deteriorated bridges under vehicle impacts. Engineering Structures, 74(1), 128-136. 